\title{
INVESTIGATION THE OLIGOMERIZATION PROCESS OF HEXENE-1
}

\author{
Ibragimov Hikmet Jamal Alizade Shahla Allahverdi., Amirov Fariz Ali., Aliyev FarizRamik \\ Institute of Petrochemical Processes named after Academician \\ Yu.H.Mamedaliyev, Baku, Azerbaijan.
}

\begin{abstract}
In article for oligomerization and alkylation processes, to obtain a useful and highly stable active catalyst, New Catalytic Complex (NCC) synthesized which is based on aluminum metal using $\mathrm{C}_{2} \mathrm{H}_{4} \mathrm{Cl}_{2}$ and this complex has shown high stability in alkylation, oligomerization processes compared to other aluminum-containing catalysts. It is difficult to regulate the molecular mass distribution of received products during oligomerization, either Intensificate the oligomerization process of olefins that is why this process take place in presence of obtaining of bimetal catalytic complex with a highly stable activity from the modification of the New Catalytic Complex(NCC) with transition metal chloride. Comparatively studied oligomerization of Hexen-1 in present of new bimetallic catalytic complex which was modified by NCC and chromium salt $\left(\mathrm{NCC} / \mathrm{CrCl}_{3}\right.$ ), effect of temperature, reaction time, concentration of the catalyst and the proportion of catalyst components $(\mathrm{Al}: \mathrm{Cr})$ in the process was investigated.It was determined that at the initial time (10 min) conversion hexene-1 and the yield of purposeful oil fraction were low. Increasing time, conversion rate of Hexen-1 increases and the optimal time for the process is considered as 60 minutes. In low concentrations of catalyst $(0,1-0,3)$ oligomerization of hexene-1 is low but in high concentrations $(>1 \%)$ reaction goes with high rate, at optimal concentration $0,5 \%$ mass both the yield of oil fraction and its chemical-physical properties were high.In oligomerization process investigated ratio effect of catalyst components $\mathrm{Al}$ : $\mathrm{Cr}$ that was used $\mathrm{Al}$ : $\mathrm{Cr}=(4-32): 1$ mol.It has been revealed that oligomerization of Hexen-1, at low mol ratio of components $(4: 1)$, received yield of oligomer fraction decreases while mol ratio increases $(16: 1,32: 1)$.Studies determined that bimetallic complex at 8:1 mole has shown the maximal activity in oligomerization process of Hexen-1.The effect of the temperature on the oligomerization process was studied in the range of $30-60^{\circ} \mathrm{C}$, increasing the temperature up to 50 ${ }^{\circ} \mathrm{C}$ has a positive effect on the course of the process and despite providing complete oligomerization of hexene-1 its also providing increasing the amount of oil fractions with high viscosity. According to the researches, the optimal conditions for the oligomerization process of hexene- 1 with the participation of the bimetallic catalytic complex: reaction time -60 min., concentration of catalyst $-0,5 \%$ by wt., mol ration of components $\mathrm{Al}: \mathrm{Cr}=8: 1$, temperature $-50{ }^{\circ} \mathrm{C}$. In known optimal condition its possible to obtain oligomers with physical indications, characterized by narrow molecular mass distribution, by new catalytic complex that was modified by chromium salt.Such products have special importance, as low-freezing, high viscosity index qualitative engine oils.Synthesis of bimetallic catalytic complexes, with their presence in oligomerization of olefins and fractions, opens wide range perspectives in synthesis of different high-molecular compounds in industry.
\end{abstract}

\section{Keywords:new catalytic complex; oligomerization; hexene-1, oligomers, synthetic oils INTRODUCTION}

Technical progress prevents the friction of different mechanisms, increasing the role of lubricants, as the most important elements of the technique, that's why different requirements for their quality are emerged and increased. Petrol oils (mineral oils) do not obey to modern technical requirements of exploitation.

In this regard, synthesis of multifunctional lubricants which must obey modern requirements is one of the main problems facing scientists. It is known that synthetic oils can be obtained by oligomerization and cooligomerization of $\alpha$ olefins.

Nowadays widely used polyalphoolefin oils play a special and more important role in the production of new lubricants with high performance properties. Chemical composition of polyalphoolefin oil (PAOO) shows itself as wide molecular weight distribution characterized by branched long chain aliphatic hydrocarbons. These lubricants are distinguished by their high viscosity index, low freezing temperature, can be used in a wide range of temperatures ranging from $-65^{\circ} \mathrm{C}$ to $230^{\circ}$, differing from mineral oils with high thermal stability. PAOO can be completely mixed with petrol oils; it is easily adaptable with additives, ecologically safe. This oils used as engine, aviation, transmission, white oils, refrigerators, vacuum-based oils, or oil lubricants such as base components.

It should be noted that processing of raw materials by modern methods allow to regulate physical and chemical properties of products at a wide range and improving new methods for the quality of oils.

\section{EXPERIMENTAL}

For oligomerization and alkylation processes, to obtain a useful and highly stable active catalyst, New Catalytic Complex (NCC) synthesized which is based on aluminum metal using $\mathrm{C}_{2} \mathrm{H}_{4} \mathrm{Cl}_{2}$ and this complex has shown high stability in alkylation, oligomerization processes compared to other aluminum-containing catalysts. In this article presented intensification of the oligomerization process of olefins, regulation of molecular mass distribution of received products during oligomerization in presence of NCC, which is based on obtaining of bimetal catalytic complex with a highly stable activity from the modification of the NCC with transition metal chloride. For this purpose, a new bimetallic catalytic complex was synthesized by modifying NCC catalyst by $\mathrm{Cr}(\mathrm{III})$ chloride. The synthesis of bimetal complexes was carried out in situ with the introduction of metal compounds into the system at the time of the emerging radicals as a result of the interaction of $\mathrm{Al}+\mathrm{DCE}$. Influence of transition metals on catalytic centers in bimetallic complexes, their nature and structure were studied by physical methods. 


\section{RESULTS AND DISCUSSION}

The synthesized bimetallic catalytic complex was studied in the oligomerization process of hexene-1. The oligomerization of hexene-1 with the presence of $\mathrm{NCC}$ and $\mathrm{NCC} / \mathrm{CrCl}_{3}$ was comparatively studied; effectof temperature, reaction time, concentration of the catalyst and the proportion of catalyst components (Al:Cr) in the process was investigated.

Table 1. The effect of reaction time in oligomerization process of hexene-1 with the presence of $\mathrm{NCC} / \mathrm{CrCl}_{3}$ (concentration of catalyst $-0.5 \%$ wt., temperature $-50^{\circ} \mathrm{C}$ )

\begin{tabular}{|c|c|c|c|c|c|}
\hline \multirow{2}{*}{$\begin{array}{c}\text { Reaction time } \\
\text { min. }\end{array}$} & \multicolumn{4}{|c|}{ Yield of oligorimation product, $\%$} & Loss, \\
\cline { 2 - 6 } & Fr.300 ${ }^{\circ} \mathrm{C}$ & Fr.300-350 $\mathrm{C}$ & Fr.350-450 $\mathrm{C}$ & Fr.450 $\mathrm{C}$ & 1,5 \\
\hline 10 & 58 & 22,5 & 16 & 5 & 2,8 \\
\hline 20 & 49,7 & 19,7 & 22,8 & 7 & 1,2 \\
\hline 30 & 38 & 17,8 & 36 & 5,8 & 2,1 \\
\hline 40 & 25,5 & 20 & 46,6 & 4,1 & 2,8 \\
\hline 50 & 11,6 & 29,5 & 52 & 3,4 & 1,2 \\
\hline 60 & 7 & 34 & 54,4 & 3,6 & 1,3 \\
\hline 70 & 6,8 & 33 & 55,3 & & \\
\hline
\end{tabular}

As seen from Table 1, at first 10 min.transformation of hexene- 1 is low and therefore, the $\mathrm{T} \leq 300^{\circ} \mathrm{C}$ fraction predominates at the oligomerization product. Increasing the reaction time increases the yield of high molecular weight oligomers and fraction of $300-450^{\circ} \mathrm{C}$ in $60 \mathrm{~min}$. has maximum yield of the oil fraction. Increasing time does not practically affect the process and the optimal time for the process is 60 min. may be considered.

During the experiments, it is identified that the rate of oligomerization hexene-1 directly depends on the catalyst's concentration (picture 1).

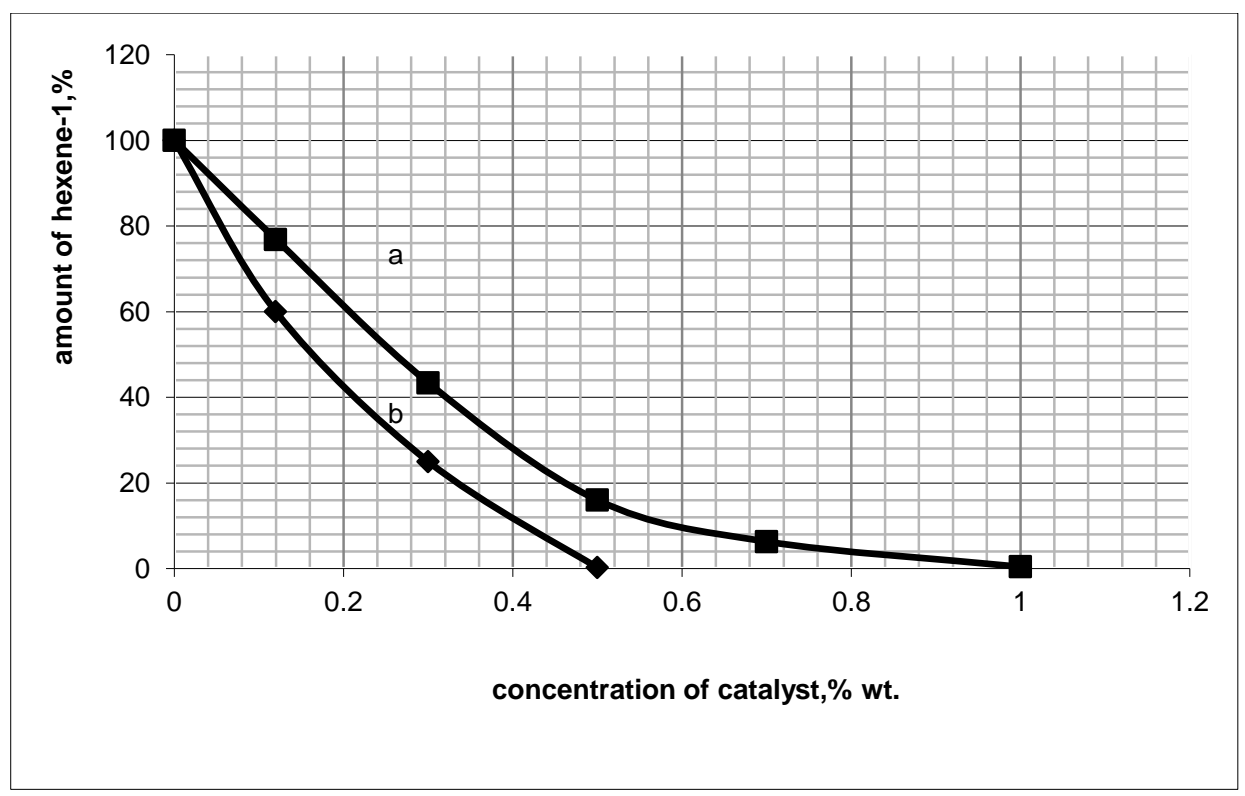

Figure 1. The effect of catalyst concentration in oligomerization of hexene-1:

$$
\text { a- NCC; b- } \mathrm{NCC} / \mathrm{CrCl}_{3}
$$

As shown in the figure, at low concentrations of catalysts $\mathrm{NCC}$ and $\mathrm{NCC} / \mathrm{CrCl}_{3}(0.1 \%)$ the oligomerization of hexene1 has proceeded weak and the yield of oligomerization products is between $40-60 \%$, depending on the nature of the catalytic system. As a result of increasing the amount of catalysts in the system, the oligomerization process is 
accelerating and the complete conversion of olefins is achieved at $0.5-1.0 \%$ by wt. concentration. Should be noted that the bimetallic catalytic complex is more active in this process compared with NCC and provides quite high activity in low concentration (0.4-0.5\%), providing hexene-1 practically full oligomerization. Giving more than $1.0 \%$ of the catalyst concentration to the system causes oligomerization of hexene-1 and the process can not be controlled.

Influence of $\mathrm{Al}: \mathrm{Cr}$ ratio on oligomerization process included in various bimetallic complex studied in $1 \mathrm{~mol}$ ratio $\mathrm{Al}: \mathrm{C}$ $r=(4-32): 1$ (Picture 2).

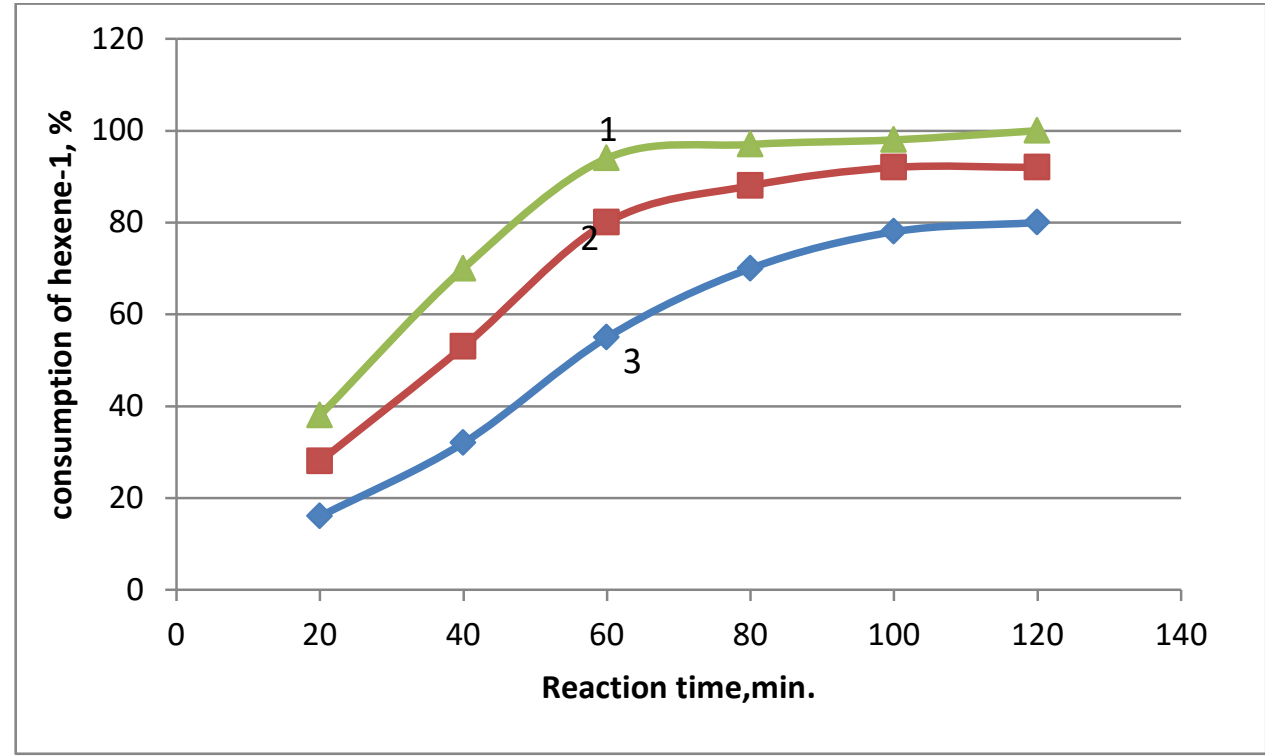

Figure 2. The dependency of different mole ratios (1 - Al: $\mathrm{Cr}=8: 1 ; 2-16: 1 ; 3-32: 1)$ on the oligomerization time of hexene-1 with the presence of $\mathrm{NCC} / \mathrm{CrCl}_{3}$

In low mole ratio of components (4:1) metal salt, which forms the complex, provides complete formation of bimetal centers, but the remaining $\mathrm{CrCl}_{3}$ precipitate from the system as a mechanical mixture. The catalytic complex obtained at this ratio also shows itself in the process of oligomerization of hexene-1, the yield of the received oligomer fraction decreases sharply. It has been determined that bimetallic complex with $8: 1 \mathrm{~mol}$ is the most active in oligomerization process of hexene-1 (Pic. 1) and oligomerization product of hexene-1 decreases as this ratio increases from (8:1) to $(32: 1)$. Note that, based on experiments; it was found that the conversion of 32:1 mole was slightly different from the transformation of hexene- 1 by the presence of NCC.

In oligomerization process, the effect of the temperature was investigated in $30-60^{\circ} \mathrm{C}$ interval. Experimental results show that increasing temperature to $50^{\circ} \mathrm{C}$ has a positive effect to the process and not only guarantees complete oligomerization of hexene-1, it also provide increasing amount of oil fraction which has high viscosity (table 2).

Table 2. Effect of temperature to oligomerization of hexene-1 in presence of $\mathrm{NCC} / \mathrm{CrCl}_{3}$ (concentration of catalyst $-0.5 \%$ wt., reaction time $-60 \mathrm{~min}$.)

\begin{tabular}{|c|c|c|c|c|c|c|}
\hline \multirow{2}{*}{$\begin{array}{c}\text { Temperature, } \\
{ }^{\circ} \mathrm{C}\end{array}$} & \multirow{2}{*}{$\begin{array}{c}\text { Conversion, } \\
\text { \% wt.. }\end{array}$} & \multicolumn{4}{|c|}{ Yield of oligorimation product,\% wt. } & \multirow{2}{*}{$\begin{array}{l}\text { Loss, } \\
\% w t\end{array}$} \\
\hline & & $<300^{\circ} \mathrm{C}$ & $300-350^{\circ} \mathrm{C}$ & $350-450^{\circ} \mathrm{C}$ & $>450^{\circ} \mathrm{C}$ & \\
\hline 30 & 60 & 5,1 & 30,7 & 48,4 & 12,6 & 3,2 \\
\hline 40 & 72 & 6,2 & 32,1 & 50,3 & 8,3 & 3,1 \\
\hline 50 & 100 & 7 & 34 & 54,4 & 3,4 & 1,2 \\
\hline 60 & 100 & 8,3 & 31,2 & 57 & 2,1 & 1,4 \\
\hline
\end{tabular}

At its seen from table 2, the maximum yield of $300-450^{\circ} \mathrm{C}$ and $>450^{\circ} \mathrm{C}$ oil fractions in the presence of $\mathrm{NCC} / \mathrm{CrCl}_{3}$ oligomerization process is observed at $50^{\circ} \mathrm{C}$ and the result is $91.8 \%$. 


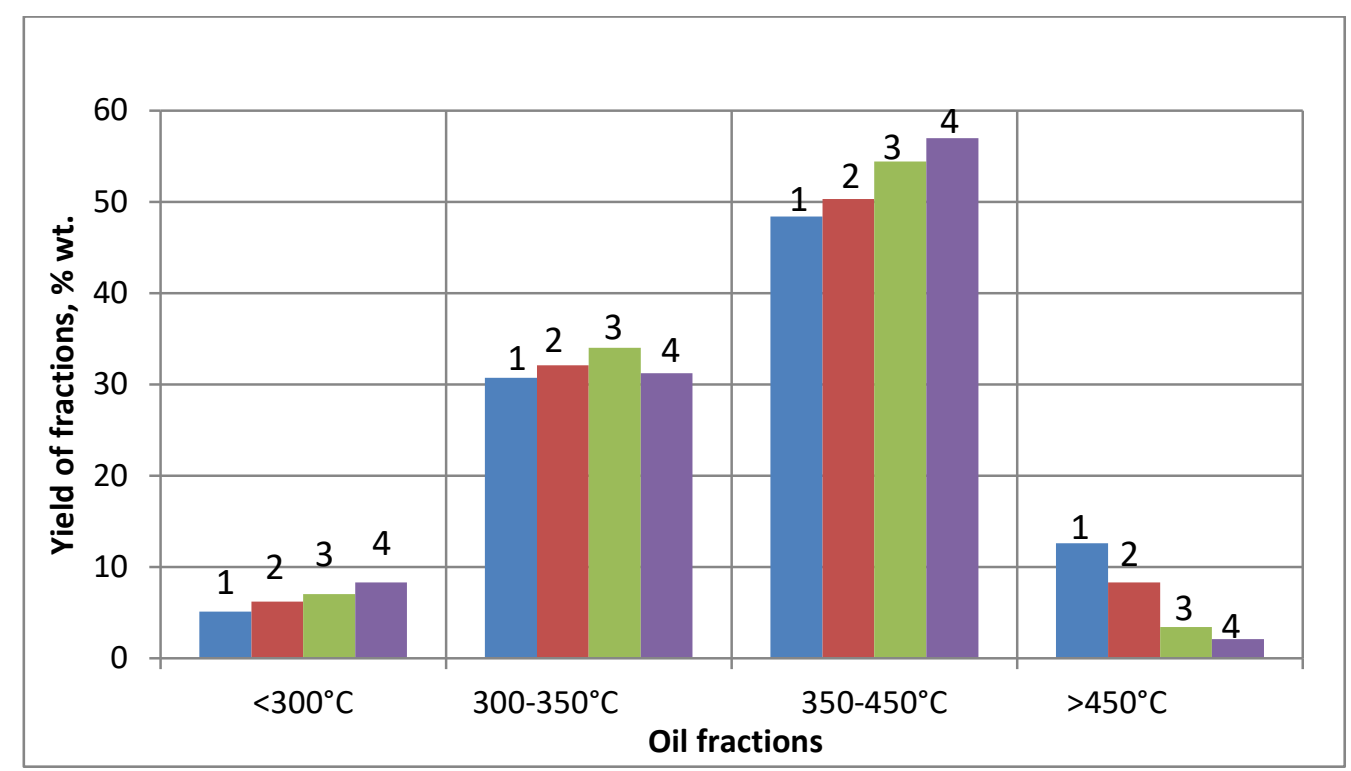

Figure 3. Yield of oil fractions from oligomerization of hexene-1 at different temperatures $\left(1-30^{\circ} \mathrm{C}, 2-40^{\circ} \mathrm{C}, 3-50^{\circ} \mathrm{C}, 4-60^{\circ} \mathrm{C}\right)$

\section{CONCLUSION}

According to the researches, the optimal conditions for the oligomerization process of hexene-1 with the participation of the bimetallic catalytic complex: reaction time -60 min., concentration of catalyst $-0.5 \%$ by wt., mol ration of components $\mathrm{Al}: \mathrm{Cr}=8: 1$, temperature $-50^{\circ} \mathrm{C}$.

As it is shown in the table below (Table 3 ) detected that, it is possible to obtain oligomers with physical indications, characterized by narrow molecular mass distribution which obtains at optimum conditions by new catalytic complex that was modified by chromium salt.

Table 3. Data of products that results from oligomerization of hexene-1 inpresent of $\mathrm{NCC}$ and $\mathrm{NCC} / \mathrm{CrCl}$ (concentration of catalyst $-0.5 \%$ mass., reaction time -60 min., temperature $-50^{\circ} \mathrm{C}$ )

\begin{tabular}{|c|c|c|}
\hline \multirow{2}{*}{ Indicators of $\mathrm{T}>350^{\circ} \mathrm{C}$ oil fraction } & \multicolumn{2}{|c|}{ Catalysts } \\
\hline & NCC & $\mathrm{NCC} / \mathrm{CrCl}_{3}$ \\
\hline Yield, \% (depending on total amount of oligomerization product) & 84 & 92 \\
\hline Density & 0,8334 & 0,8366 \\
\hline Viscosity, $\mathrm{mm}^{2} / \mathrm{sec} ., 100^{\circ} \mathrm{C}$ & 4,3172 & 6,488 \\
\hline Viscosity index & 120 & 122 \\
\hline Refraction index & 1,4625 & 1,4632 \\
\hline lodine unit, grY/100gr & 5,14 & 4,55 \\
\hline Flash point, $\stackrel{\circ}{\mathrm{C}}$ & 220 & 234 \\
\hline Freezing point, $\stackrel{\circ}{\mathrm{C}}$ & -48 & -43 \\
\hline
\end{tabular}

Thus, with the presence of aluminum based bimetallic catalytic system, during the oligomerization process allows to get more superior physical-chemical properties of oil fraction, which can use as quality engine oils. 


\section{REFERENCES}

1. Kolesova G.E. Abstract of candidate of science. Moscow VNII NP, 2001.

2. IbragimovKh.D., Alizadeh A.A., Ibragimova Z.M. perspective for the synthesis of polyalphaolefin oils // Azerbaijan National Academy of Science Institute of Petrochemical Processes named after Academician Yu.H.Mamedaliyev. Petrochemicals and oil refining processes. 16.3(63), 2015, p.265280.

3. Kotov S.V, Moiseev I.K, Shabanova A.V. Oligomers of olefins: methods of preparation and use as components of fuels and oils. Petrochemistry, 2003, vol. 43, No. 5, p. 233-334

4. Matkovsky P.E, Startseva G.P, ChurkinaV.Ya. and etc. Scientific foundations and technological design for the process of obtaining synthetic oligodecene oils for road transport. // Chemistry in interest of stable development 2005, No. 13, p.787-791

5. Liu J, Shen H B, Wang M. Synthesis of high viscosity index PAO[J]. Synthetic Lubricants, 2006, 33(1), p.13-15

6. Guseinova G.A. Technological aspects of obtaining synthetic olefin white oils. // Oil refining and petrochemistry, 2006, №7, c.21-25

7. Ibragimov H.J., Gasimova K.M., Ibragimova Z.M., Kolchikova I.V., Khalaf M.M., Alieva A.E. Synthesis and study of bimetallic catalytic systems formed in situ by aluminum, 1, 2-dichloroethane and Fe (III), $\mathrm{Ni}$ (II), Mn (II) chlorides // Journal of Advances in Chemistry. 2013. 3(1). p.120-132

8. Ibragimov H.C., Ismailov E.H., Gasimova K.M., Yusifov Y.H., Ibragimova Z.M., Kolchikova I.V. Bimetallic aluminum complexes modified with chloride lons of $\mathrm{Mn}$ (II), $\mathrm{Fe}$ (III), and $\mathrm{Ni}$ (II) for pyrocondensateoligomerization // International Research Journal of Pure \& Applied Chemistry. 2013. 3(4). P.428-440

9. Ibragimov H.J., Gasimova K.M., Ibragimova Z.M., Gasimova G.F.. Synthesis of Petroleum Polymer Resin by Catalytic Polymerization of Pyrocondensate and Its Fractions // American Chemical Science Journal. 2014. 4(1). p.82-96

10. Pat. I. 20020001 Az. R.Rustamov MI, Babaev Al, Farhadova GT, Kyazimov S.M. Method for the preparation of a catalyst for the conversion of hydrocarbons. 2002.

11. Kh. D. Ibragimov, KM Kasumova, Z. Ibragimov, Sh.A.Alizade, I.V. Kolchikova, S. M. Aleskerov Application of nano-sized carbon aluminum-containing bimetallic catalytic complexes in oligomerization processes. // Azerbaijan Chemical Journal, 2016, №4, p.64-68.

12. Eric J. Goethals, Filip Du Prez. Carbocationic polymerizations // Progress in Polymer Science. 2007. v.32. No 2. p.220-246

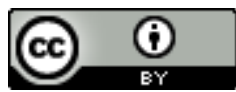

This work is licensed under a Creative Commons Attribution 4.0 International License.

D O I : 10.24297/jac.v14i1.6455 